\title{
The New Electrical Engineering Curriculum at the University of Southern California
}

\author{
H. H. Kuehl, J. M. Mendel \\ University of Southern California
}

\section{INTRODUCTION}

In November, 1993, the University of Southern California Electrical Engineering Department created a task force to review the undergraduate curriculum and develop a new and innovative electrical engineering curriculum. The task force, comprised of faculty representatives from all fields of electrical engineering within the Department, devoted many hours during a period of three years to a thorough review and a substantial revision of the undergraduate curriculum. This paper describes the resulting new curriculum, which became effective in the fall of 1996. During the creation of the new curriculum, the task force was guided by several broad principles and desired objectives which the members believed were of major importance to a superior and relevant undergraduate curriculum. These included:

\section{A. Fundamentals}

The undergraduate curriculum must provide a basic grounding in the fundamentals of mathematics, basic sciences, engineering, as well as appreciable content in humanities and social sciences.

\section{B. Flexibility}

A greater opportunity for choice is appropriate, including a wider variety of up-to-date specializations from which students may choose.

\section{Depth}

A limited degree of specialization in at least one area of the major is desirable in order to prepare the graduate adequately to enter the engineering profession.

\section{Breadth}

Breadth in the major field is of prime importance to engineers involved in the development of the innovative products in today's rapidly changing workplace.

\section{E. Design}

The EE graduate must have the capability to delineate and solve in a practical way the engineering problems which are encountered during his/her career. Engineering design is usually a major component of the solution process; thus, the undergraduate curriculum should include a substantial design experience.

\section{F. Reduction in Total Units}


The total number of required units should be reduced, if possible, from the existing number in order to facilitate graduation within four years.

\section{G. Innovation}

The new curriculum should contain distinctive and innovative features which derive from particular strengths at USC and which set it apart from other EE programs.

\section{THE NEW CURRICULUM}

\section{A. Overview of Electrical Engineering Requirements}

A good overview of the electrical engineering requirements and options of the new curriculum can be obtained from the diagram shown in the figure. In this diagram, the central region contains the core courses, which are required of all EE students, and are discussed in Sec. II. B.

The ring surrounding the central area of the diagram is divided into four sectors which are labeled with the four topical areas into which modern electrical engineering can be divided: (1) Communication, Control, and Signal Processing, (2) Computer Engineering, (3) Electromagnetics and Energy Conversion, and (4) Electronic Devices and Circuits. Under each of the four topical areas are listed two "entry-level courses," which are prerequisites to most of that area's more advanced courses. Students are required to take all of the entry-level courses in three of the four areas. The topical areas together with their entry-level courses are discussed in Sec. II. C.

The more advanced courses are listed in the outermost ring of the diagram, and are grouped into thirteen areas of specialization. Students are required to complete at least one area of specialization. Areas of specialization are discussed in Sec. II. D.

In addition to the electrical engineering requirements and options indicated in the figure, there are other course and unit requirements which are discussed in Sec. II. E.

\section{B. Core Courses}

As shown in the diagram, the core EE courses are:

EE 101 (3 units) Introduction to Digital Logic

EE 105 (3 units) Introduction to Electrical Engineering

EE 202L (4 units) Linear Circuits

EE 301a (3 units) Introduction to Linear Systems

EE 330 (3 units) Electromagnetics I

EE 364 (3 units) Introduction to Probability and Statistics for Engineers

These courses are required of all EE majors. They were chosen in order to provide students with a solid foundation in the basic fundamentals of both the electrophysics and systems areas of electrical engineering.

EE 105 is a new introductory course which was developed to excite students about electrical engineering, to teach key generalizable concepts, and to anticipate the second-through-fourth year curriculum. A well-known problem encountered with beginning engineering students is that they 
have a very limited understanding of what a practicing engineer actually does. In electrical engineering this is compounded by the extremely diverse nature of the field, which encompasses

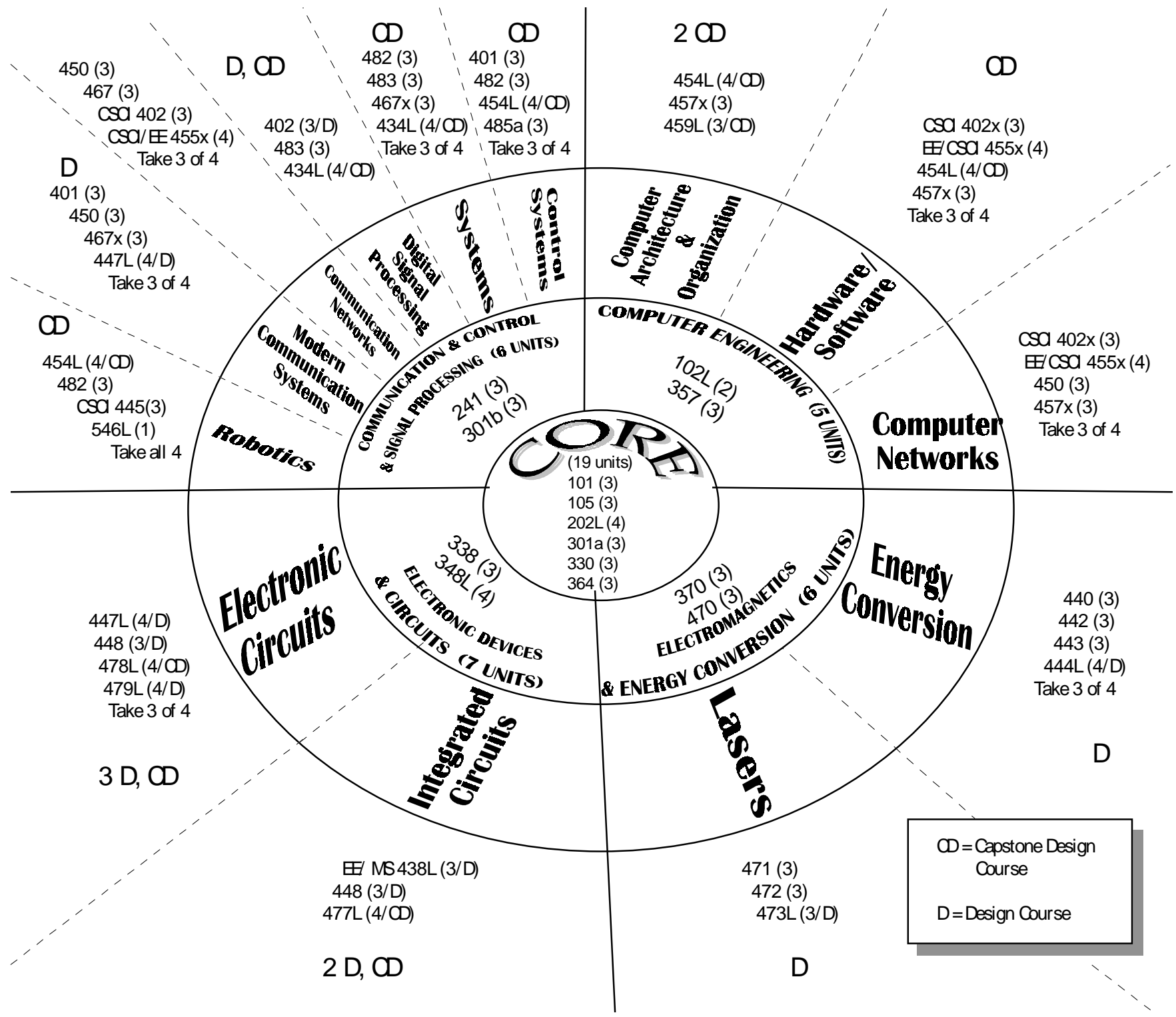

a wide variety of areas of manufacturing, research, development, and design, ranging from electric motors to fuzzy logic. A primary objective of EE 105 is to give the beginning EE student an overview of many of these areas. It utilizes several novel features including a multimedia theme throughout, "hands-on disassembly" of equipment familiar to students, such as a fax machine, modem, copier, laser printer, and computer. Furthermore, there is extensive use of multimedia tools and simulation techniques in class, and there is a collaborative teamwork design emphasis. The course, which was offered for the first time in the spring 1997 semester, is team taught by two of the top teachers on the EE faculty in order that it be presented in a stimulating and enthusiastic manner to motivate students to continue their studies in electrical engineering, i.e., this course can be an important factor in the retention of students in EE. 
EE 301a is a course that emphasizes the transform approach to solving problems in controls, communications and signal processing. The focus of the course is on continuous time systems, which ensures a smooth transition from another core course, EE 202L, Linear Circuits, focusing first on linear circuits and then on other types of systems to give the student a more global perspective of systems. The next course in this sequence is EE 301b, which is an entry-level course in the Communication, Control, and Signal Processing topical area, which focuses primarily on discrete-time systems.

EE 330, Electromagnetics I, is a substantial revision of the first electromagnetics course in the previous curriculum. The reason for the revision is that, in the new curriculum, EE 330 may be the only electromagnetics course taken by a student if he/she does not choose the Electromagnetics and Energy Conversion topical area. Therefore, in the new version, the time spent studying statics is reduced in order to make room for other topics considered to be more important in modern applications.

EE 364 is a new introductory course on probability and statistics that also includes bounded uncertainty and fuzzy logic. It is course that is intended to reinforce the fact that this is not a deterministic world. About half of the semester is spent on probability and the other half on statistics and other ways to characterize uncertainty.

\section{Topical Areas and Entry Level Courses}

As shown in the figure, the ring surrounding the central core courses is divided into four sectors which represent the broad topical areas into which modern electrical engineering can be divided. In each sector are listed two courses which are the "entry-level courses" for that topical area. These entry-level courses are the prerequisites to most of that area's more advanced courses contained in the areas of specialization (shown in the outer ring). The four topical areas together with the associated entry-level courses are:

1. Communication, Control, and Signal Processing

EE 241 Applied Linear Algebra for Engineers

EE 301b Introduction to Linear Systems

2. Computer Engineering

EE 102L Introduction to Digital Logic

EE 357 Basic Organization of Computer Systems

3. Electromagnetics and Energy Conversion

EE 370 Electromechanics

EE 470 Electromagnetics II

4. Electronic Devices and Circuits

EE 338 Physical Electronics

EE 348L Electronic Circuits I

Students are required to choose 3 of the 4 areas and to complete all the entry-level courses in the three chosen areas. The completion of the entry-level courses in three areas ensures that each student has adequate breadth in electrical engineering, a definite asset in the career of most electrical engineers. While a college program which emphasizes narrow specialization may be advantageous in the first few years after graduation, it may be a detriment later on because most careers in engineering require an ability to work in more than one area. 


\section{Areas of Specialization}

The more advanced courses are listed in the outermost ring of the figure, and are grouped into areas of specialization, each of which represents, in most cases, a cohesive group of related courses in a specialized topic. Students are required to complete at least one area of specialization, although more than one are allowed. The reason for this requirement is to ensure that each student's program of study provides some depth in at least one area of electrical engineering. In the figure, the areas of specialization are arranged so they lie in the particular sector which corresponds to their general topical area. Also, the prerequisites for the courses in a particular area of specialization are, in most cases, the entry-level courses in that topical area (together with the core courses). Also indicated in the figure are the number of design (D) and capstone design (CD) courses in each area of specialization. The new curriculum requires three design courses, of which at least one must be a capstone design course. It may be noted that, for some areas of specialization, one or more design or capstone design courses must be taken outside the area of specialization. Additional design courses in these areas are being developed to eliminate this shortcoming. Several of the areas of specialization contain new courses which were developed specifically for these new areas. A listing of the areas of specialization and their courses is given in the Appendix.

\section{E. Other Requirements}

In addition to the requirements involving core courses, entry-level courses, and areas of specialization discussed in the previous sections, there are several other requirements in the new curriculum:

(1) The total number of units for the BSEE is 131, which is a reduction from the previous 135 unit requirement, and will facilitate graduation within four years.

(2) A course in either engineering economy or in technical entrepreneurship is required. The course in technical entrepreneurship is new; it is described in Sec. II. F.

(3) An introductory computer course is required in the freshman year. This course provides a basic introduction to computers, computer programming, the USC computing environment, and to skills which permit the student to design and implement solutions to engineering problems.

(4) A new course in oral and written communication, described in Sec. II. F, is required, in addition to a freshman composition course.

(5) Undergraduates are required to satisfy an ethics requirement, by including in their humanities and social science electives one of several courses which have been developed specifically to include a substantial component of engineering ethics issues.

(6) Three design courses, including one capstone design course, are required.

(7) A non-EE engineering science elective course is required.

(8) One chemistry and three physics courses are required.

(9) Five mathematics courses, including calculus, differential equations, and engineering mathematics, are required.

(10) Twenty units of humanities and social science electives are required.

\section{F. Innovation}


The new USC undergraduate EE curriculum has several innovative features which we believe set it apart from many other curricula:

(1) A unique course in engineering "communications and innovation" is required in the freshman year. This course, which was developed jointly by the Schools of Engineering and Business, focuses on technical communication skills, including multimedia presentations, and uses major engineering advances, and the leadership required to accomplish these advances, as subject matter for the written and oral communication exercises. Thus, in addition to training in technical communication, this course is intended to foster the leadership qualities of students, which has been identified as a principal attribute desired by the industries which hire engineering graduates.

(2) In addition to the two formal communications courses in the freshman year, the new curriculum incorporates oral and written communication exercises in designated engineering courses throughout the four years of the undergraduate program.

(3) A wide spectrum of up-to-date technical areas of specialization is available

to students. Additional areas of specialization are being developed with interdisciplinary elements.

(4) A new course in technical entrepreneurship has been introduced, which is available to students as an alternative to the course in engineering economy. This course, which has been developed jointly with the School of Business, provides essential tools for economic decision making in new ventures, which is important because more of our students are pursuing non-traditional career paths in which they join smaller firms or start up their own companies. Moreover, many large firms are creating new start-up divisions as they adjust to declines in the defense industry. This course is particularly appropriate to the EE Department's mission to prepare its graduates for leadership positions. It will expand their horizons to the possibility to choose new entrepreneurial career paths they might not have otherwise considered.

(5) A minor in multimedia and creative technologies is available to electrical engineering undergraduates. This is an interdisciplinary minor which includes courses in the departments of Electrical Engineering, Cinema-Television, Computer Science, Fine Arts, and Music. It provides students with the skill necessary to compete in the multimedia technology industry.

(6) A minor in music recording is available to electrical engineering undergraduates through the School of Music. It provides students with the background necessary to enter the field of recording engineering and to familiarize them with the design needs of modern recording equipment. This minor is especially appropriate to electrical engineering majors with musical training who would like to combine their technical and musical abilities while learning the engineering aspects of music recording.

(7) In addition to the areas of specialization described in Sec. II. D, there are two "areas of emphasis" available to undergraduates: (i)Computers and (ii) Manufacturing Engineering. An area of emphasis is a specific focus within a major which is more extensive and requires more course work than an area of specialization. The Manufacturing Engineering option is an interdisciplinary option in conjunction with the departments of Industrial and Systems Engineering, Mechanical Engineering, Computer Science, and Materials Science, and was developed under the Southern California Coalition for Education in Manufacturing Engineering, of which USC is a member. 


\section{CONCLUSIONS}

A new undergraduate electrical engineering curriculum has been developed at the University of Southern California. Compared with the previous curriculum, the new curriculum has more flexibility, in that the number of required courses has been reduced substantially to increase free electives and allow a greater degree of customization around the personal interests and goals of individual students. To this end, a wide spectrum of up-to-date areas of specialization has been developed. Although flexibility and choice have been increased, the curriculum also requires courses which provide a basic grounding in mathematics, sciences, engineering, as well as a distinctive experience in humanities and social sciences. To ensure breadth in electrical engineering, the entry-level courses in three of the four topical areas are required of all students. A certain degree of depth in electrical engineering is provided by the requirement of the courses in at least one of the areas of specialization. Extensive exposure to oral and written communication skills is provided by two formal communications courses, as well as substantial communication exercises in designated engineering courses throughout the four years of the undergraduate program. Engineering ethical issues are addressed in courses in humanities and social science which have been designed explicitly to expose students to ethical problems they may face on the job. A newly developed introduction to electrical engineering course provides a hands-on motivational experience in the freshman year. In addition, the new curriculum has several unique interdisciplinary courses and options, which include: A course in communication and innovation and a course in technical entrepreneurship, both of which were developed jointly with the School of Business; A minor in multimedia and creative technologies, in conjunction with the departments of Cinema-Television, Computer Science, Fine Arts, and Music; A minor in music recording through the School of Music. Moreover, an option in computer engineering is available, as well as an interdisciplinary manufacturing engineering option in conjunction with the departments of Industrial and Systems Engineering, Mechanical Engineering, Computer Science, and Materials Science. 


\section{APPENDIX. AREAS OF SPECIALIZATION}

\section{Communication, Control, \& Signal Processing}

Control Systems( take 3 of 4)

EE $401 \quad$ Transform theory for engineers

EE 454L Introduction to systems design using microprocessors

EE $482 \quad$ Linear control systems

EE485a Digital control systems

\section{Systems(take 3 of 4)}

EE 434L Digital signal processing design laboratory

EE 467x Introduction to communication systems

EE $482 \quad$ Linear control systems

EE 483 Introduction to digital signal processing

\section{Digital Signal Processing}

EE 402Design of analog and digital filters

EE 434L Digital signal processing design laboratory

EE 483Introduction to digital signal processing

Communication Networks(take 3 of 4)

EE 450Introduction to computer networks

$\mathrm{EE} / \mathrm{CS} 455 \mathrm{x}$ Introduction to programming systems design

EE 467x Introduction to communication systems

CS 402x Operating systems

Modern Communication Systems( take 3 of 4)

EE 401Transform theory for engineers

EE 447L Mixed signal electronic circuits

EE 450Introduction to computer networks

$\mathrm{EE} 467 \mathrm{x} \quad$ Introduction to communication systems

Robotics( take all 4)

EE 454L Introduction to systems design using microprocessors

EE 482Linear control systems

EE 546L Basic robotics laboratory

CS 445Introduction to robotics

\section{Computer Engineering}

\section{Computer Architecture and Organization}

EE 454L Introduction to systems design using microprocessors EE 457Computer systems organization

EE 459L Senior design project 
Hardware/Software( take 3 of 4)

CS 402x Operating systems

$\mathrm{EE} / \mathrm{CS} 455 \mathrm{x}$ Introduction to programming systems design

EE 454L Introduction to systems design using microprocessors

EE 457x Computer systems organization

Computer Networks(take 3 of 4 )

CS 402x Operating systems

$\mathrm{EE} / \mathrm{CS} 455 \mathrm{x}$ Introduction to programming systems design

EE 450 Introduction to computer networks

EE 457x Computer systems organization

\section{Electromagnetics \& Energy Conversion}

Energy Conversion( take 3 of 4)

EE $440 \quad$ Rotating electrical machinery

EE 442 Direct energy conversion

EE 443 Introduction to power systems

EE 444L Introduction to high-efficiency power conversion

Lasers

EE 471

EE 472

EE473L
Applied quantum mechanics for engineers Introduction to lasers and laser systems

Lasers and optics laboratory

\section{Electronic Devices \& Circuits}

Electronic Dircuits(take 3 of 4)

EE 447L Mixed signal electronic circuits

EE $448 \quad$ Electronic circuits II

EE 478L Digital electronic circuit design

EE 479L Introduction to integrated circuit design

\section{Integrated Circuits}

EE/MS 438L Processing for microelectronics

EE 448Electronic circuits II

EE 477L MOS VLSI circuit design

HANS H. KUEHL

Hans H. Kuehl received his B. S. from Princeton University and his M. S. and Ph. D. from the California Institute of Technology, all in Electrical Engineering. He has received the USC Associates Award for Teaching Excellence, the highest teaching award at the University of Southern California. His research interests include wave-plasma interactions. He is Professor and Chairman of the Electrical Engineering-Electrophysics Department at USC.

JERRY M. MENDEL

Jerry M. Mendel is Professor of Electrical Engineering, Director of Special Educational Projects for the School of Engineering, and Associate Director for Education of the Integrated Media Systems Center, at the University of Southern California in Los Angeles, where he has been since 1974. He has published over 325 technical papers and is the author or editor of seven books. 